\title{
Intergenotypic effect of isopropanol ingestion in the further detoxification of ethanol and isopropanol in Drosophila melanogaster
}

\author{
E. Guillén, \\ F. J. S. Sánchez-Cañete, \\ J. J. Garrido, \\ G. Dorado and \\ M. Barbancho*
}

\begin{abstract}
Departamento de Genética, Facultad de Ciencias,
\end{abstract} Universidad de Córdoba, 14071 Córdoba, Spain.

The effect of isopropanol ingestion on a further tolerance to ethanol and isopropanol, and its relationship with the $A d h$ locus, have been studied using Drosophila melanogaster selected for tolerance to ethanol. For this purpose, $A d h^{\mathrm{F}} A d h^{\mathrm{F}}$, $A d h^{\mathrm{F}} A d h^{\mathrm{S}}$ and $A d h^{\mathrm{S}} A d h^{\mathrm{S}}$ flies were independently pretreated with 2 per cent isopropanol and then further exposed to solutions of 10 per cent ethanol or of 2 per cent isopropanol. Afterwards, the ability to tolerate both alcohols, and the ADH activities of the surviving flies were compared with those of flies not pretreated with isopropanol. After isopropanol ingestion, the flies of all three $A d h$ genotypes shown much higher sensitivity to ethanol than to isopropanol although the opposite results were observed in flies not pretreated with isopropanol. Isopropanol treatment decreased the ADH activity in flies of all three genotypes within a range varying from 73 per cent (females FF) to 93 per cent (males FS), the remaining ADH activity being between 2 to 3 times higher in FF than in FS and SS flies. The reduction in $\mathrm{ADH}$ activity was associated with the phenomenon of $\mathrm{ADH}$ isozyme interconversion. After the isopropanol pretreatment, the most isopropanol tolerant flies (FF) were also the most ADH active ones. Therefore, the adaptative significance of the isozyme conversion is questioned.

\section{INTRODUCTION}

It is well known that the alcohol dehydrogenase enzyme (ADH) plays an essential role in the detoxification of alcohols in Drosophila (David et al., 1976, 1981, 1984; Deltombe-Lietaert et al., 1979). The ADH enzyme of Drosophila catalyses the oxidation of primary and secondary alcohols into aldehydes and ketones, respectively (Day et al., 1974; David et al., 1978; Heinstra et al., 1983; Gonzàlez-Duarte and Atrian, 1986). In particular, $\mathrm{ADH}$ transforms ethanol and isopropanol into acetaldehyde and acetone, respectively. Nevertheless, aldehydes and ketones are more toxic than their corresponding alcohols (David et al., 1976, 1981). Moreover, while primary alcohols (as ethanol) can be used as energy sources through a further aldehyde metabolisation, the secondary alcohols (as isopropanol) cannot. That leads to the accumulation of ketones into the flies, and their

\footnotetext{
* To whom correspondence and reprint requests should be sent.
}

eventual excretion (David et al., 1976, 1981; van Herrewege et al., 1980; Dorado and Barbancho, 1984; Gonzàlez-Duarte and Atrian, 1986; SánchezCañete et al., 1986).

The effects of isopropanol or acetone ingestion have been studied in different species of Drosophila: D. melanogaster (Vilageliu and Gonzàlez-Duarte, 1980; Anderson and McDonald, 1981; David et al., 1981; Sánchez-Cañete et al., 1986), D. buzzatii (Fontdevila et al., 1980), $D$. funebris and $D$. immigrans (Vilageliu and Gonzàlez-Duarte, 1984; Gonzàlez-Duarte and Vilageliu, 1985), D. simulans, D. mauritanica, $D$. yakuba and D. teisseri (Gelfand and McDonald, 1983), D. mojavensis (Batterham et al., 1983), and D. hydei (Gonzàlez-Duarte and Atrian, 1986). It has been found that the ingestion of isopropanol or acetone by Drosophila brings about substantial changes in the alcohol dehydrogenase. The exposure of $D$. melanogaster to isopropanol or acetone causes a dramatic increase in activity of the ADH-1 form of the enzyme (the most anodaly 
migrating), which is associated with two molecules of a NAD-carbonyl compound. Such exposure also provokes a considerable decrease in the activity of the ADH-5 form of the enzyme (the most cathodaly migrating), which is not associated with any molecule of the NAD-carbonyl compound. This process has been named "interconversion" and results in a significant decrease of total ADH activity, concomitant with an increase in the stability and concentration of the enzymes (Jacobson et al., 1970, 1972; Schwartz and Sofer, 1976; Papel et al., 1979; Schwartz et al., 1979; Vilageliu and Gonzàlez-Duarte. 1980; Anderson and McDonald, 1981).

Gonzàlez-Duarte and Atrian (1986) have observed, after exposing $D$. hydei to isopropanol, an increase in activity of an aldo-keto reductase (AKR), another enzyme involved in alcohol tolerance. Moreover, this change occurred simultaneously with the decrease in ADH activity. The AKR can use acetone and acetaldehyde as substrates, transforming them into isopropanol and ethanol, respectively (Vilageliu and GonzàlezDuarte, 1980). Similar effects to both the decrease in ADH activity and the interconversion, have been described in all the above mentioned species of Drosophila, and a similar increase in AKR activity in some of them. However, there seem to exist further relationships between ADH and the secondary alcohols, because the in vitro assays show that: (a) ADH is much more active on secondary alcohols such as isopropanol, than on primary ones such as ethanol (Day et al., 1974; Morgan, 1975; Oakeshott, 1976; Chambers et al., 1978; Barbancho et al., 1987), and (b) ADH plays an important role in the detoxification of isopropanol and acetone, two compounds which are not used as energy sources (David et al., 1976, 1981; McDonald and Avise, 1976; Sánchez-Cañete et al., 1986).

In view of the fact that acetone has a substantially greater toxic effect than isopropanol, a decrease in ADH activity, like the one observed when flies are fed with isopropanol, would slow down the rate of production of acetone, and thereby would enhance the ability of the flies to survive in an isopropanol containing medium. Additionally, an increase in AKR activity would partially transform the acetone produced into isopropanol, preventing its accumulation in the flies. Due to these facts, it has been suggested that the interconversion could have an adaptative significance in Drosophila (Papel et al., 1979; Fontdevila et al., 1980; Anderson and McDonald, 1981; Gonzàlez-Duarte and Atrian, 1986). Since flies with higher ADH activity show a greater tolerance to isopropanol (van Delden et al., 1975; McDonald and Avise, 1976; David et al., 1981; SánchezCañete et al., 1986), under the hypothesis of the adaptative interconversion, the flies with higher ADH activities should show the greater reductions in this enzyme activity after exposure to isopropanol.

The present paper aims to study the question mentioned above. For that purpose, flies of FF, FS and SS genotypes were independently exposed to distilled water, to a 10 per cent ethanol solution or to a 2 per cent isopropanol solution. The viabilities and the $\mathrm{ADH}$ activities of the surviving populations of each sex and genotype were measured. Afterwards, the survivors from isopropanol pretreatment were exposed again to water, to a 10 per cent ethanol or to a 2 per cent isopropanol solution. Finally, their viabilities and ADH activities were measured and compared with those of the flies without isopropanol pretreatment, as explained below.

\section{MATERIALS AND METHODS}

\section{Drosophila strains}

Two strains of Drosophila melanogaster were used: homozygous for the $A d h^{\mathrm{F}}$ allele (FF), homozygous for the $A d h^{\mathrm{s}}$ allele (SS). The heterozygotes (FS) were generated by crossing the two strains. The homozygous strains came from LRSe lines, which had been independently selected for tolerance to ethanol. Both strains were continuously maintained on food containing an 11 per cent $(\mathrm{v} / \mathrm{v})$ of ethanol. More details about the strains and culture conditions are described elsewhere (Dorado and Barbancho, 1984).

\section{Mortality and $A D H$ activity measurements}

In order to determine adult mortality, samples from the three lines used were grown for one generation on regular food and 3-day-old flies from these cultures were fed one more day on fresh regular food. These flies were then put one day into hermetically closed vials containing $3 \mathrm{ml}$ of either distilled water, or a 10 per cent $(v / v)$ ethanol solution, or a 2 per cent $(\mathrm{v} / \mathrm{v})$ isopropanol solution. Each vial contained a piece of absorbent cotton $(0.4 \mathrm{~g})$ in its bottom, soaked with $3 \mathrm{ml}$ of the testing solution. The cotton was covered by a round piece of Whatman No. 3 filter paper. A minimum set of three replicates was made for each tested sample, and each vial contained 10 males and 10 females. The mortality and ADH activity of males and 
females were determined after this period of time. ADH activity was assayed in the surviving flies. The survivors from the vials containing the 2 per cent isopropanol solution, were afterwards transferred into new vials containing the three solutions referred to above, and after one day more (6-dayold flies) the mortality and ADH activity of males and females were determined.

For measuring ADH activity, samples of 20 adults (males and females, separately) were homogenised in $1 \mathrm{ml}$ of cold $0.05 \mathrm{M}$ Tris $-\mathrm{HCl}$ buffer $p \mathrm{H} 8 \cdot 6$. Then, the homogenates were centrifuged $\left(10,000 \mathrm{~g}, 10\right.$ minutes, $\left.4^{\circ} \mathrm{C}\right)$ and the supernatants used as the source of enzyme. ADH activity was determined by following the reduction of $\mathrm{NAD}^{+}$at $340 \mathrm{~nm}$. The reaction solution contained $0.8 \mathrm{ml}$ of $0.05 \mathrm{M}$ Tris- $\mathrm{HCl}$ buffer $\mathrm{pH} 8.6,0.6 \mathrm{ml}$ of $4 \mathrm{mM} \mathrm{NAD}^{+}$in the same buffer, $0.1 \mathrm{ml}$ of isopropanol, and $20 \mathrm{ul}$ of the enzyme extract. The increase of absorbance in the reaction solution was registered in a Beckman 24 double-beam recording spectrophotometer, at $30^{\circ} \mathrm{C}$. One unit of $\mathrm{ADH}$ activity is defined as the amount of enzyme which reduces $1 \mu \mathrm{mol}$ of $\mathrm{NAD}^{+}$per minute under assay conditions. A minimum of two replicates was measured in each case.

\section{Electrophoresis}

For each sample, one fly was homogenised and then subjected to electrophoresis in starch gel, at $30 \mathrm{~mA}$ for 6 hours. The ADH bands were stained after Ayala et al. (1972).

\section{RESULTS}

Fig. 1 (left) shows the ADH activities from homogenates of male and female adults of SS, FS and FF $A d h$ genotypes after 1 day on either distilled water $(\mathrm{O})$, or a 10 per cent ethanol solution (E) or a 2 per cent isopropanol solution (I). For a better comparison between ADH activities and adult mortalities, the last ones are also represented in fig. 1. Additionally, lower part of fig. 1 depicts a diagram showing the electrophoretic pattern of $\mathrm{ADH}$ allozymes under the different experimental conditions.

As expected, after 1 day on water (O), FF flies displayed higher ADH activities than SS ones, the FS being intermediate. The same ADH activity pattern can be seen when the flies were kept on a 10 per cent ethanol solution $(E)$, which is indicat-

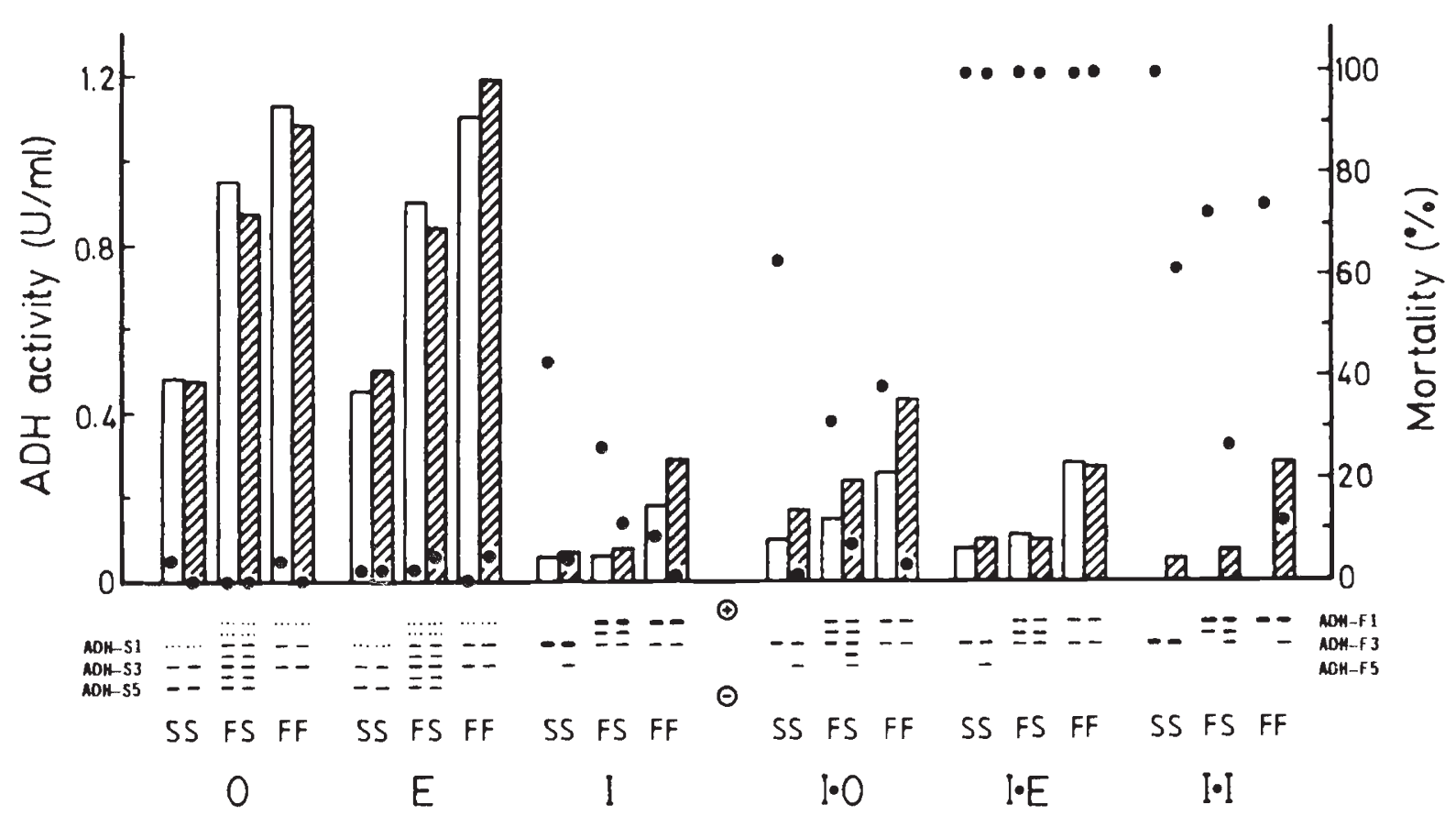

Figure 1 Upper: ADH activities ( $\square$ : males; 伎: females) and mortalities ( ) of flies from SS, FS and FF Adh genotypes, after 1 day of exposure to water (O), to a 10 per cent ethanol solution (E) or to a 2 per cent isopropanol solution (I). The experiments were carried out without $(\mathrm{O}, \mathrm{E}$ and $\mathrm{I}$, respectively) and with $(\mathrm{I} \cdot \mathrm{O}, \mathrm{I} \cdot \mathrm{E}$ and $\mathrm{I} \cdot \mathrm{I}$, respectively) a previous exposure of the flies to a 2 per cent isopropanol solution for 1 day. Lower: Electrophoretic patterns of mobility of ADH-S and ADH-F allozymes from flies exposed to the different experimental conditions. 
ing that the ethanol treatment has not induced the ADH activity in the flies. Moreover, no changes were observed in the electrophoretic pattern of the ADH bands of flies from ethanol (E) when compared with that of flies from water $(\mathrm{O})$.

On the other hand, the 10 per cent ethanol solution was well tolerated by the flies. In fact, mortalities on ethanol were very low and similar to those found on the control solution. This can also be seen in table $1(\mathrm{E})$, where the changes of both ADH activities and mortalities are calculated.

When the flies were exposed for 1 day to a 2 per cent isopropanol solution, the ADH activities of both males and females of all three genotypes were drastically reduced (fig. 1 ; I). The percentages of reduction are indicated in table 1 (I). Under such conditions, the SS and FS flies exhibited similar ADH activities. However, FF flies continued showing higher activities than SS and FS individuals (fig. 1; I). In fact, the FF flies were those in which the decrease in ADH activity was lower (Table 1; I). It is well documented (see Introduction) that the isopropanol-mediated ADH activity reduction is associated to an interconversion of the ADH isozymes from the more cathodaly migrating forms towards the more anodaly migrating ones. This interconversion is shown for the SS, FS and FF genotypes in lower part of fig. 1 (I).

In relation to the mortalities, the males were less tolerant to the isopropanol than the females of the same genotype (fig. 1 ; I), and the FF flies of a particular sex were the ones showing the lowest absolute values (fig. $1 ; \mathrm{I}$ ) and the lowest increases in mortality (table $1 ; \mathrm{I}$ ).

In fig. 1 (right) are also represented the $\mathrm{ADH}$ activities, the mortalities and the ADH electrophoretic patterns of males and females of SS, FS and FF Adh genotypes which, after one day on a 2 per cent isopropanol solution, were kept 1 day more on water $(\mathrm{I} \cdot 0)$, or on a 10 per cent ethanol solution (I.E), or on a 2 per cent isopropanol solution (I.I). Table 1 indicates the corresponding changes in ADH activity and mortality.

As expected (Papel et al., 1979; GonzàlezDuarte and Atrian, 1986), after 1 day on water, the ADH activity of flies of all three genotypes (which had previously been kept on the isopropanol solution) increased. This seems to be greater in the females and in flies of FS genotype (table $1 ; \mathrm{I} \cdot \mathrm{O}$ ), which is in agreement with the electrophoretic pattern of FS females, in which some of the more cathodaly bands have already appeared (fig. 1; I.O). On the other hand, the increase in mortality was only moderate in the males, whereas the females showed similar or lower death rates after 1 day on isopropanol and then one day more on water (see also table 1; I - O). Probably, these differences are due to the fact that the females of LR lines are more resistant to starvation than the males (Dorado and Barbancho, 1984).

Interesting results were found when the flies kept 1 day on the isopropanol solution were trans-

Table 1 Percentages of the changes in ADH activity and in mortality of flies from SS, FS and FF genotypes under different conditions

\begin{tabular}{|c|c|c|c|c|c|c|c|}
\hline \multirow[b]{2}{*}{$\begin{array}{l}\text { Exposure conditions } \\
\text { (subtraction) }\end{array}$} & \multirow[b]{2}{*}{ Trait studied } & \multicolumn{6}{|c|}{ Genotype and sex } \\
\hline & & $\delta$ & $q$ & $\partial$ & q & $\partial$ & q \\
\hline $\begin{array}{l}E \\
(E-O)\end{array}$ & $\begin{array}{l}\text { ADH Activity } \\
\text { Mortality }\end{array}$ & $\begin{array}{l}-6 \cdot 2 \\
-1 \cdot 5\end{array}$ & $\begin{array}{l}+5 \cdot 3 \\
+2 \cdot 5\end{array}$ & $\begin{array}{l}-5 \cdot 3 \\
+2 \cdot 5\end{array}$ & $\begin{array}{l}-4 \cdot 0 \\
+5 \cdot 0\end{array}$ & $\begin{array}{l}-2 \cdot 7 \\
-4 \cdot 0\end{array}$ & $\begin{array}{l}+9 \cdot 7 \\
+5 \cdot 0\end{array}$ \\
\hline $\begin{array}{l}\mathrm{I} \\
(\mathrm{I}-\mathrm{O})\end{array}$ & $\begin{array}{l}\text { ADH Activity } \\
\text { Mortality }\end{array}$ & $\begin{array}{l}-87 \cdot 5 \\
+40 \cdot 0\end{array}$ & $\begin{array}{r}-85 \cdot 3 \\
+5 \cdot 0\end{array}$ & $\begin{array}{l}-93 \cdot 1 \\
+27 \cdot 0\end{array}$ & $\begin{array}{l}-90 \cdot 8 \\
+12 \cdot 0\end{array}$ & $\begin{array}{r}-84 \cdot 1 \\
+5 \cdot 0\end{array}$ & $\begin{array}{r}-73 \cdot 3 \\
+1 \cdot 0\end{array}$ \\
\hline $\begin{array}{l}\mathrm{I} \cdot \mathrm{O} \\
(\mathrm{I} \cdot \mathrm{O}-\mathrm{I})\end{array}$ & $\begin{array}{l}\text { ADH Activity } \\
\text { Mortality }\end{array}$ & $\begin{array}{l}+66 \cdot 7 \\
+19 \cdot 0\end{array}$ & $\begin{array}{r}+143 \cdot 0 \\
-4 \cdot 0\end{array}$ & $\begin{array}{r}+150 \cdot 0 \\
+5 \cdot 0\end{array}$ & $\begin{array}{r}+200 \cdot 0 \\
-4 \cdot 5\end{array}$ & $\begin{array}{l}+38 \cdot 9 \\
+29 \cdot 0\end{array}$ & $\begin{array}{r}+48 \cdot 3 \\
+1 \cdot 5\end{array}$ \\
\hline $\begin{array}{l}I \cdot E \\
(I \cdot E-1)\end{array}$ & $\begin{array}{l}\text { ADH Activity } \\
\text { Mortality }\end{array}$ & $\begin{array}{l}+33 \cdot 3 \\
+56 \cdot 0\end{array}$ & $\begin{array}{l}+25 \cdot 0 \\
+95 \cdot 0\end{array}$ & $\begin{array}{l}+83 \cdot 3 \\
+68 \cdot 0\end{array}$ & $\begin{array}{l}+25 \cdot 0 \\
+88 \cdot 0\end{array}$ & $\begin{array}{l}+55 \cdot 5 \\
+91 \cdot 0\end{array}$ & $\begin{array}{r}-6 \cdot 9 \\
+99 \cdot 0\end{array}$ \\
\hline $\begin{array}{l}I \cdot I \\
(I \cdot I-I)\end{array}$ & $\begin{array}{l}\text { ADH Activity } \\
\text { Mortality }\end{array}$ & $\begin{array}{l}\text { ND } \\
+56 \cdot 0\end{array}$ & $\begin{array}{l}-21 \cdot 4 \\
+57 \cdot 0\end{array}$ & $\begin{array}{l}\text { ND } \\
+46 \cdot 0\end{array}$ & $\begin{array}{l}-12 \cdot 5 \\
+15 \cdot 0\end{array}$ & $\begin{array}{l}\text { ND } \\
+65 \cdot 0\end{array}$ & $\begin{array}{r}-3 \cdot 4 \\
+11 \cdot 5\end{array}$ \\
\hline
\end{tabular}

Data for mortalities represent the differences between the mortality percentages of the two conditions compared. Data for ADH activities show the differences between the values of the two conditions compared, expressed as percentages of the values of the reference experimental condition (O or $\mathrm{I}$ ).

ND: no data. For other abreviations and exposure conditions see legend of fig. 1. 
ferred for one day more to a 10 per cent ethanol solution, or to a new 2 per cent isopropanol solution (fig. $1 ; \mathrm{I} \cdot \mathrm{E}$ and I $\cdot \mathrm{I}$, respectively). Independently of the sex or the genotype, a few hours after the flies were transferred into the vials containing the ethanol solution, all the individuals had died. Immediately, the ADH activities were assayed, and the results are represented in fig. 1. Apparently, the flies had not had time enough to recuperate the ADH activity in the presence of ethanol (compare it with the increase in activity after a second day on water) (fig. 1 and table $1 ; \mathrm{I} \cdot \mathrm{E}$ and $\mathrm{I} \cdot \mathrm{O}$, in both). Besides that, both the model of ADH activities and the $\mathrm{ADH}$ electrophoretic pattern after the second day on ethanol (I E E), were more similar to those after the first day on isopropanol (I), than to the ones after 1 day on isopropanol and 1 day more on water (I · O) (fig. 1 ).

Additionally, flies kept 2 days on an isopropanol solution (fig. 1; I I I) showed lower mortalities than flies proceeding from isopropanol that had been kept 1 day more on a 10 per cent of ethanol (fig. 1; I-E). Males, with the exception of SS, displayed (after a second day on isopropanol), mortalities lower than 75 per cent, and the females lower than 63 per cent, the FF females even showing a mortality as low as 12.5 per cent.

Furthermore, after a second day on the isopropanol solution, a new but smaller reduction in the ADH activity was observed in all three genotypes (fig. 1; I I I). However, this reduction was again lower in FF flies (table $1 ; \mathrm{I} \cdot \mathrm{I}$ ), the FF females having the highest ADH activity (fig. 1; I - I). The activity of the males was not assayed because after 2 days on isopropanol not enough individuals survived the treatment. On the other hand, after 2 days on the isopropanol solution, the interconversion of the ADH bands towards the most anodaly forms was more evident, as the electrophoretic pattern represented in fig. 1 (I I I) shows.

\section{DISCUSSION}

In general, our results agree with earlier studies in which flies of Drosophila, fed with isopropanol or acetone, exhibited dramatic changes in ADH activity, associated to the phenomenon of the enzymatic interconversion (Schwartz and Sofer, 1976; Papel et al., 1979; Fontdevila et al., 1980; Vilajeliu and Gonzàlez-Duarte, 1980; Anderson and McDonald, 1981; Gonzàlez-Duarte and Atrian, 1986). We have observed that after 24 hours of exposure to isopropanol, there was a considerable decrease in total ADH activity in flies from all three $A d h$ genotypes (SS, FS and FF) (fig. 1; I). Additionally, there was also an increase in the amount of the ADH-1 form of the enzyme, the most electronegative one. However, there were not significant changes in the ADH activity of SS, FS and FF flies which had been exposed to ethanol (fig. 1;E).

Due to the different effects that primary and secondary alcohols have on the ADH isozymes, the isopropanol- or acetone-mediated interconversion has been interpreted as having some adaptative significance (Papel et al., 1979; Anderson and McDonald, 1981). A decrease in ADH activity in flies exposed to isopropanol would reduce the rate of accumulation of acetone, thereby preventing its toxic effect. Thus, it should be expected that after a treatment with isopropanol, the flies showing lower ADH activities should also present lower mortalities. However, our results do not support that assumption. In fact, the flies displaying the highest $\mathrm{ADH}$ activities, both $\mathrm{FF}$ males and females, manifested the lowest mortalities after an exposure to isopropanol (fig. 1; I). Even more, when flies deficient in ADH activity were exposed one day more to isopropanol, it was found again that the mortality was lower when the ADH activity happened to be higher (fig. 1; I - I). On the other hand, these results are consistent with those of van Delden et al. (1975), McDonald and Avise (1976), David et al. (1981), and our previous findings (Sánchez-Cañete et al., 1986), where it was reported that higher tolerance to isopropanol of flies was associated with higher ADH activity. Therefore, our results support the conclusion of David et al. (1981) that ADH must play a significant role in the detoxification of isopropanol, although this alcohol is not used as energy source. However, our data do not agree with the hypothesis of ADH interconversion as having an adaptative value (after isopropanol treatment the flies with lower mortalities also showed higher ADH activities), unless other loci besides the $A d h$ locus were involved in the phenomenon. In relation to this, Atrian and Gonzàlez-Duarte (1985) have detected an AKR (aldo keto reductase) activity in $D$. melanogaster ADH-null flies, which can transform acetone into isopropanol. Furthermore, D. hydei flies treated with isopropanol exhibited an AKR induction associated to the reduction of $\mathrm{ADH}$ activity, which has been interpreted as a mechanism to protect the flies against the more toxic effects of acetone (Gonzàlez-Duarte and Atrian, 1986). It is likely that the AKR could also be induced by 
isopropanol in D. melanogaster adults, though it has not been described so far. If such AKR induction occurs in $D$. melanogaster, FF flies (the most $\mathrm{ADH}$ active and the most tolerant to isopropanol) should also have the highest AKR activity after an isopropanol treatment, when compared to SS and FS flies. Under this assumption, the isopropanol tolerance should correlate inversely with the ratio $\mathrm{ADH} / \mathrm{AKR}$ activity. Further studies must be done to test this hypothesis.

On the other hand, our results also demonstrate that $\mathrm{ADH}$ activity plays an indispensable role in the detoxification of ethanol. Flies of all three genotypes were very tolerant to ethanol (fig. $1 ; \mathrm{E}$ ), but when exposed to isopropanol and then to ethanol, they were unable to detoxificate the ethanol and thus died (fig. 1; (I - E). Similar results were found by Papel et al. (1979), who observed that flies with reduced ADH activity by the previous exposure to 0.5 per cent acetone, were much more sensitive to ethanol. However, our data indicate that the flies deficient in ADH activity were substantially more tolerant to isopropanol (2 per cent) than to ethanol (10 per cent), although in the control flies, isopropanol was equally or more toxic than ethanol (fig. 1). In fact, the flies deficient in $\mathrm{ADH}$ activity died a short time after being exposed to ethanol, when their ADH activities were still very low, and when the most active forms of the enzyme had not been yet newly synthesised (fig. 1; I.E). Apparently, when the products of the oxidation of alcohols cannot be metabolised, they tend to accumulate in the flies (the case of isopropanol and its corresponding acetone). Under these conditions, a decrease in ADH activity brings about an increase in the tolerance to the alcohols, as a consequence of the reduction of their secondary toxicity. However, the products of the oxidation of primary alcohols are further metabolised (the case of ethanol and its corresponding acetaldehyde). In such circumstances, a decrease in ADH activity brings about a decrease in the tolerance to the alcohols, as a result of the increase of their primary toxicity. This is supported by the study of Papel et al. (1979), in which the loss of ADH activity by a previous treatment with 0.5 per cent acetone, brought about an increase in the sensitivity to ethanol, a decrease in sensitivity to pentenol (a secondary unsaturated alcohol the oxidised product of which, ethyl vinyl ketone, is a highly toxic compound), and an inability to use the ethanol as energy source. Similar results have been obtained recently in our laboratory when flies of both FF and SS genotypes with reduced ADH activity (by previous treatment with isopropanol), were exposed to both ethanol and pentenol (data not shown).

The increase in sensitivity to ethanol after the ADH activity reduction, could also be explained as a consequence of an increase of the secondary toxicity of ethanol. If, as suggested by Heinstra $e t$ al. (1983), ADH not only catalyses the oxidation of ethanol to acetaldehyde but additionally catalyses the oxidation of this highly toxic product into acetate, a reduction in ADH activity could enhance the toxic effects of the acetaldehyde by preventing its detoxification into acetate. Under this assumption, the acetaldehyde produced from the ethanol would be enough to kill the flies. However, David et al. (1984) claimed that the aldehyde metabolising enzyme system in Drosophila is not ADH, explaining the higher sensitivity to acetaldehyde of the ADH-negative flies (when they are compared to wild type ones) by the transformation of the aldehyde into alcohol.

In conclusion, our study shows that, in $D$. melanogaster adults, the ingestion of isopropanol (a secondary alcohol) brings about an increase in sensitivity to ethanol (a primary alcohol) and likely a decrease in sensitivity to isopropanol. The loss of ADH activity through the phenomenon of enzymatic interconversion seems to be essential in these changes of sensitivity. Nevertheless, if the phenomenon of interconversion has an adaptative significance, other enzymes besides ADH must be involved.

Acknowledgements We thank M. I. G. Roncero for critical reading of the manuscript.

\section{REFERENCES}

ANDERSON, S. M. AND MCDONALD, J. F. 1981. A method for determining the in vivo stability of Drosophila alcohol dehydrogenase (E.C.1.1.1.1.). Biochem. Genet., 19, 411419 .

ATRIAN, S. AND GONZÀLEZ-DUARTE, R. 1985. An aldo-keto reductase activity in Drosophila melanogaster and Drosophila hydei: A possible function in alcohol metabolism. Comp. Biochem. Physiol., 81B, 949-952.

AYAlA, F. J., POWELL, 3. R., TRACEY, M. L., MOURÃO, C. A. AND PÉREZ-SALAS, S. 1972. Enzyme variability in the Drosophila willistoni group. IV. Genic variation in natural populations of Drosophila willistoni. Genetics, 70, 113-139.

BARBANCHO, M., SÁNCHEZ-CAÑETE, F.J.S., DORADO G. AND PINEDA, M. 1987. Relation between tolerance to ethanol and alcohol dehydrogenase (ADH) activity in Drosophila melanogaster: Selection, genotype and sex effects. Heredity, $58,443-450$

BATTERHAM, P., LOVETT, 3. A., STARMER, W. T. AND SULLIVAN, D. T. 1983. Differential regulation of duplicate alcohol dehydrogenase genes in Drosophila mojavensis. Dev. Biol., 96, 346-354. 
CHAMBERS, G. K., MCDONALD, J. F., McELRESH, M. AND AYAlA, F. J. 1978. Alcohol oxidizing enzymes in 13 Drosophila species. Biochem. Genet., 16, 757-767.

DAVID, J. R., BOCQUET, C., ARENS, M. F. AND FOUILLET, P. 1976. Biological role of alcohol dehydrogenase in the tolerance of Drosophila melanogaster to aliphatic alcohols: Utilization of an ADH-null mutant. Biochem. Genet., 14, 989-997.

DAVII, J. R., BOCQUET, C., HERREWEGE, J. VAN, FOUILLET, P. AND ARENS, M. F. 1978. Alcohol metabolism in Drosophila melanogaster: Uselessness of the most active aldehyde oxidase produced by the Aldox locus. Biochem. Genet., 16, 203-211.

DAVID, J. R. DALY, K. AND HERREWEGE, J. VAN 1984. Acetaldehyde utilization and toxicity in Drosophila adults lacking alcohol dehydrogenase or aldehyde oxidase. Biochem. Genet., 22, 1015-1029.

DAVID, J. R., HERREWEGE, J. VAN, SCHEEMAEKER-LOUIS, M. DE, AND PLA, E. 1981. Drosophila alcohol dehydrogenase: Detoxification of isopropanol and acetone, substances not used in energy metabolism. Heredity, 47, 263-268.

DAY, T. H., HILlier, P. C. AND ClARKE, B. 1974. Properties of genetically polymorphic isozymes of alcohol dehydrogenase in Drosophila melanogaster. Biochem. Genet., 11, $141-153$.

DELDEN, W. VAN, KAMPING, A. AND DIJK, H. VAN 1975. Selection at the alcohol dehydrogenase locus in Drosophila melanogaster. Experientia, 31, 418-420.

DELTOMBE-LIETAERT, M. C., DELCOUR, J., LENELlEMONFORT, N. AND ELENS, A. 1979. Ethanol metabolism in Drosophila melanogaster. Experientia, 35, 579-581.

DORADO, G. AND BARBANCHO, M. 1984. Differential responses in Drosophila melanogaster to environmental ethanol: Modification of fitness components at the Adh locus. Heredity, 53, 309-320.

FONTDEVILA, A., SANTOS, M. AND GONZÁlEZ, R. 1980. Genotype-isopropanol interaction in the $A d h$ locus in Drosophila buzzatii. Experientia, 36, 398-400.

GELFAND, L. J. AND MCDONALD, J. F. 1983. Relationship between alcohol dehydrogenase (ADH) activity and behavioral response to environmental alcohol in five Drosophila species. Behav. Genet., 13, 281-293.

GONZȦLEZ-DUARTE, R. AND ATRIAN, S. 1986. Metabolic response to alcohol ingestion in Drosophila hydei. Heredity, 56, $123-128$.

GONZÀlez-DUARTE, R. AND VILAGEliU, L1. 1985. Metabolic response to ethanol and isopropanol in $D$. funebris and $D$. immigrans. Comp. Biochem. Physiol., 80C, 189-193.
HEINSTRA, P. W. H., EISSES, K. Th., SCHOONEN, W. G. E. J., ABEN, W., WINTER, A. J. DE, HORST, ABEN, W., WINTER, A. J. DE, HORST, D. J. VAN DER, MARREWIJK, W. J. A. VAN, BEENAKKERS, A. M. Th., SCHARLOO, W. AND THÖRIG, G. E. W. 1983. A dual function of alcohol dehydrogenase in Drosophila. Genetica, 60, 129-137.

HERREWEGE, J. VAN, DAVID, J. R. AND GRANTHAM, R. 1980. Dieatry utilization of aliphatic alcohols by Drosophila. Experientia, 36, 846-847.

JACOBSON, K. B., MURPHY, J. B. AND HARTMAN, F. C. 1970. Isozymes of Drosophila alcohol dehydrogenase. I. Isolation and interconversion of different forms. J. Biol. Chem., 245, 1075-1083.

JACOBSON, K. B., MURPHY, J. B., KNOPP, J. A. AND ORTIZ, J. R. 1972. Multiple forms of Drosophila alcohol dehydrogenase. III. Conversion of one form to another by nicotinamide adenine dinucleotide or acetone. Arch. Biochem. Biophys., $149,22-35$.

MCDONALD, F. J. AND AVISE, J. C. 1976. Ecidence for the adaptative significance of enzyme activity levels: Interspecific variation in $\alpha-\mathrm{GPDH}$ and ADH in Drosophila. Biochem. Genet., 14, 347-355.

MORGAN, P. 1975. Selection acting directly on an enzyme polymorphism. Heredity, 35, 124-127.

OAKESHOTT, J. G. 1976. Biochemical differences between alcohol dehydrogenases of Drosophila melanogaster. Aust. J. Biol. Sci., 29, 365-373.

PAPEL, I., HENDERSON, M., HERREWEGE, J. VAN, DAVID, J. AND SOFER, w. 1979. Drosophila alcohol dehydrogenase activity in vitro and in vivo: Effects of acetone feeding. Biochem. Genet., 17, 553-563.

SÁNCHEZ-CAÑETE, F. J. S., DORADO, G. AND BARBANCHO, M. 1986. Ethanol and isopropanol detoxification associated with the Adh locus of Drosophila melanogaster. Heredity, $56,167-175$

SCHWARTZ, M., O'DONNELL, J. AND SOFER, w. 1979. Origin of the multiple forms of alcohol dehydrogenase from Drosophila melanogaster. Arch. Biochem. Biophys., 194, 365-378.

SCHWARTZ, M. AND SOFER, w. 1976. Diet-induced alterations in distribution of multiple forms of alcohol dehydrogenase in Drosophila. Nature, 263, 129-131.

VILAGELIU, LI. AND GONZÀLEZ-DUARTE, R. 1980. Effect of ethanol and isopropanol on the activity of alcohol dehydrogenase, viability and life-span in Drosophila melanogaster and Drosophila funebris. Experientia, 36, 828829 .

VIllageliu, Ll. AND GONZÀlez-DUARTE, R. 1984. Alcohol dehydrogenase from Drosophila funebris and Drosophila immigrans: Molecular and evolutionary aspects. Biochem. Genet., 22, 797-815. 